\title{
INFLUENCE OF HEAT TRANSFER COEFFICIENT ON QUENCHING PROCESSES SIMULATION
}

\author{
${ }^{1}$ lliyan DANEV, ${ }^{2}$ Danail GOSPODINOV, ${ }^{3}$ Rossen RADEV, ${ }^{4}$ Mariana ILIEVA \\ 1 University of Ruse, Ruse, Bulgaria, EU, idanev@uni-ruse.bg \\ 2University of Ruse, Ruse, Bulgaria, EU, dgospodinov@uni-ruse.bg \\ 3University of Ruse, Ruse, Bulgaria, EU, rradev@uni-ruse.bg \\ 4University of Ruse, Ruse, Bulgaria, EU, mdilieva@uni-ruse.bg
}

https://doi.org/10.37904/metal.2020.3510

\begin{abstract}
Currently, heat treatment is the most common and effective method for changing the properties of metals and their alloys. Ferrous alloys most often are heat treated and the most commonly used process of heat treatment is the quenching. At quenching the final structure and material's properties are formed during the fast cooling process. Therefore, the correct choice of cooling conditions is critical for quality of quenched parts. The simulation of quenching is one of the modern approaches for researching the cooling processes. In order to obtain reliable results, the correct input data for simulation are crucial. It is commonly accepted that the heat transfer coefficient (HTC) plays most significant influence on the simulation results. Meanwhile in the specialized literature there are quite different values of HTC even at equal cooling conditions and a few data regarding its influence on the simulation results. The aim of this paper is to determine to what extent the results obtained after simulation of quenching processes are influenced by HTC. Samples of different dimensions and ratios between length and diameter (L/D), made of medium carbon steel (C45 EN 10083), were studied. Results for the influence of HTC together with geometry of the quenched parts, especially samples with different ratio length/diameter (L/D), are presented in the article.
\end{abstract}

Keywords: Quenching simulation, heat transfer coefficient, cooling ability

\section{INTRODUCTION}

The modern processing of metallic materials is inconceivable without heat treatment. The use suitable heating and cooling conditions gives a possibility for significant change in materials properties, depending on their application and the requirements made to them. It is well known that the final structure after the heat treatment process is formed during the cooling stage; this stage is therefore of particular importance for the quality of heat treated products. However, despite the work of numerous researchers on the problem, the cooling stage is still the main reason for unsatisfactory products quality after heat treatment, especially in processes requiring accelerated cooling. An advanced approach to solve the complex problem for cooling conditions selection is to reveal the relationship between the object being cooled, the cooling media and the formed structure in the bulk of the object, through simulation of cooling processes. A basic prerequisite for reliable simulation results are the correct input data. These data can be classified in three groups:

1) geometry and thermophysical properties of the object being cooled;

2) heat transfer coefficient (HTC);

3) relationship between the cooling rate and the resulting structure and properties - Time Temperature Transformation (TTT) or Continuous Cooling Transformation (CCT) diagrams. 
Though the information about the influence of the values of heat transfer coefficient on the final simulation results is insufficient, it is commonly accepted that among the input data these values are the key factor determining the correctness of predicting the simulation results. Moreover, if the information for CCT diagrams is not gathered in real experiments, the correctness of their prediction should not be underestimated as the final result regarding the structure and properties is considerably influenced by the position of the predicted cooling curves on the CTT diagrams.

There are different approaches for HTC determination as most commonly used are Lumped-heat-capacity method [1-6] and Temperature gradient method [5-15]. A feature of these methods is the need for initial information about how the temperature changes with time at one or several points in the bulk of the object being cooled. Different researchers use specimens of different materials with different shapes and dimensions; this difference in the specimens inevitably influences the registered cooling curves and therefore, it influences also the results for HTC. There are also other methods for HTC determination such as using the results of Jominy test [16-18] or using the determination of the current coolant temperature - calorimetric method [19,20]. A review of the available researches done by different authors demonstrates there are significant differences in the values and temperature distribution of HTC for same quenchants e.g. water.

The present work aims to examine and evaluate the influence of heat transfer coefficient data on the simulation results for hardenability and mechanical properties obtained after quenching simulation of rotationally symmetrical products of medium carbon steel.

\section{METHODOLOGY}

The influence of the heat transfer coefficient (HTC) on the quenching simulation results was determined using Simufact specialized software and its module Heat Treatment [21]. The input data for the continuous cooling transformation curves that, when combined with the cooling curves, gave information on the microstructure and hardness of the used in the simulation steel were determined using JMatPro specialized software [22].

For material modelling, medium carbon steel for quenching and tempering C45 (EN 10083) was used. The chemical composition of C45 according to EN 10083-2:2006 and the used for the material modelling chemical composition are shown in Table 1. In the specialized literature it is recommended C45 to be quenched from temperatures of $820 \ldots 860{ }^{\circ} \mathrm{C}$. In the present study, temperature of $860^{\circ} \mathrm{C}$ has been used for quenching simulation. The objects used in the simulation were cylindrical. The diameter $D$ and the $L / D$ ratio between length $L$ and diameter $D$ of the objects are shown in Table 2.

Table 1 Chemical composition of C45 (wt\%)

\begin{tabular}{|c|c|c|c|c|c|c|c|c|c|}
\hline Composition & $\mathbf{C}$ & $\mathbf{S i}$ & $\mathbf{M n}$ & $\mathbf{P}$ & $\mathbf{S}$ & $\mathbf{C r}$ & $\mathbf{M o}$ & $\mathbf{N i}$ & $\begin{array}{c}\mathbf{C r}+\mathbf{N i}+ \\
\mathbf{M o}\end{array}$ \\
\hline $\begin{array}{c}\text { According to EN } \\
\text { 10083 }\end{array}$ & $\begin{array}{c}0.42- \\
0.5\end{array}$ & $<0.4$ & $\begin{array}{c}0.5- \\
0.8\end{array}$ & $<0.045$ & $<0.045$ & 0.4 & $<0.1$ & $<0.4$ & $<0.63$ \\
\hline $\begin{array}{c}\text { Used for prediction of } \\
\text { CCT diagram from } \\
\text { JMatPro }\end{array}$ & 0.45 & 0.2 & 0.6 & 0.030 & 0.030 & 0.1 & - & 0.1 & 0.2 \\
\hline
\end{tabular}

Table $2 \mathrm{~L} / \mathrm{D}$ ratios and diameter of heat treatment simulated objects (all dimensions are in $\mathrm{mm}$ )

\begin{tabular}{|c|c|c|c|c|c|c|c|}
\hline \multicolumn{2}{|c|}{$\mathrm{L} / \mathbf{D}=\mathbf{0 . 1}$} & \multicolumn{3}{|c|}{$\mathrm{L} / \mathbf{D}=\mathbf{2}$} & \multicolumn{3}{c|}{$\mathrm{L} / \mathbf{D}=\mathbf{5}$} \\
\hline $\mathrm{D}=300$ & $\mathrm{D}=400$ & $\mathrm{D}=30$ & $\mathrm{D}=55$ & $\mathrm{D}=80$ & $\mathrm{D}=30$ & $\mathrm{D}=55$ & $\mathrm{D}=80$ \\
\hline
\end{tabular}

The simulations of quenching were done using data for HTC from different sources $[1,6,21,23]$ (Figure 1). 


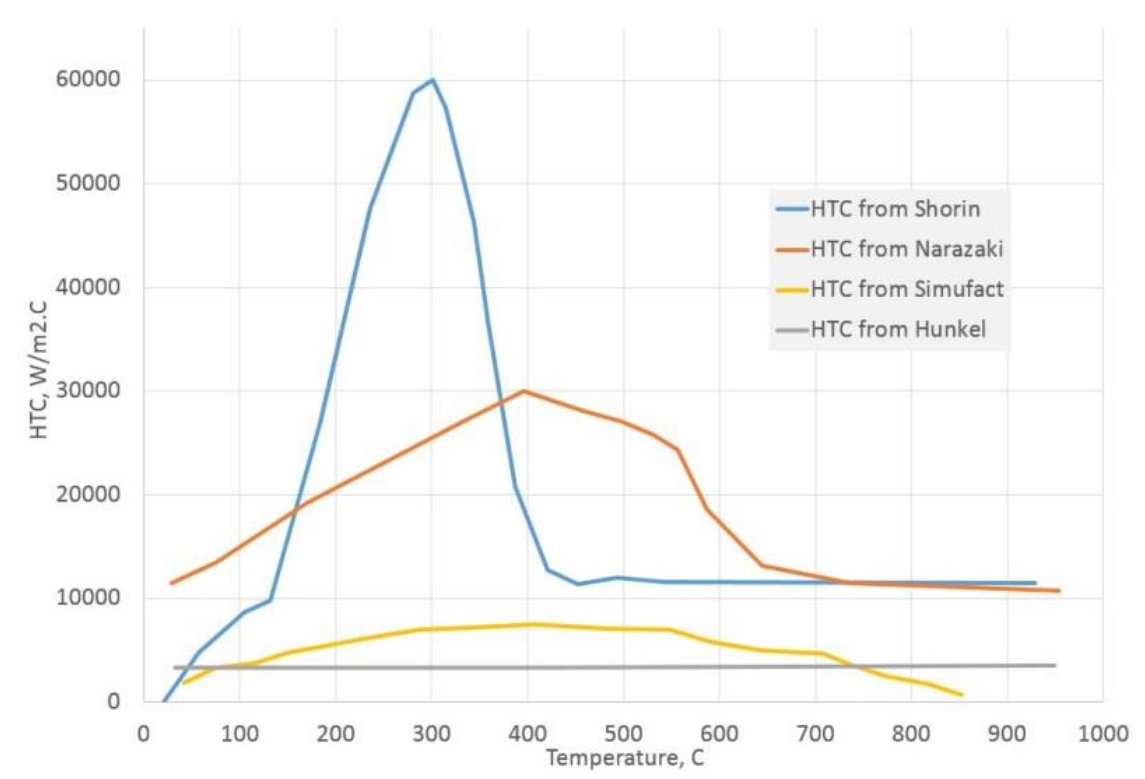

Figure 1 Values of HTC for water proposed by different researches and used for the quenching simulations $[1,6,21,23]$

Using simulations with HTC values from the above mentioned different sources results for hardness distribution, depth of hardening and critical diameter $D_{\text {crit }}$ where $50 \%$ of martensite is formed were obtained. According to [24] in quenched steel, containing $0.45 \%$ carbon the semi-martensitic zone with $50 \%$ of martensite should have a hardness of $45 \mathrm{HRC}$. Thus, hardness value of $45 \mathrm{HRC}$ was accepted as a criterion for depth of hardening and $D_{\text {crit. }}$

\section{RESULTS AND DISCUSSION}

Figure $\mathbf{2 a}$ and $\mathbf{2 b}$ show the results for hardness distribution within the bulk of the studied objects after quenching simulations using $\mathrm{HTC}$ for water according to [21]. The used in these simulations objects were with dimensions $D=300 \mathrm{~mm}, L / D=0.1$ and $D=55 \mathrm{~mm}, L / D=5$. In our work were registered and analysed hardness results only in a plane normal to the axis of the object, at a distance of $1 / 2$ the length $L$. It is known that in products with low $L / D$ ratio cooling through the frontal planes is considerable. Thus, the change in hardenability when using different values for HTC should be larger in planes parallel to the longitudinal axis, while the influence of the cooling through frontal planes on hardenability of products with $L / D$ ratio greater than four can be considered insignificant.

Graphical representations of the simulation results are presented only for objects with $L / D=5$ and diameters $\mathrm{D}=30 \mathrm{~mm}$ and $\mathrm{D}=80 \mathrm{~mm}$ (Figure 3) as the size of this report is restricted. Simulation results for the hardenability of all studied objects are summarised in Table 3 as a function of HTC values, diameters and L/D ratios.

According to Figure $3 \mathrm{a}$ and Table 3 the simulation results for the objects with diameter of $30 \mathrm{~mm}$ demonstrate that at the chosen conditions (D, L/D ratio, HTC values), regardless of the used HTC values, full hardenability of objects is to be expected. At greater diameters in all used here heat treatment simulated objects, according to the obtained in simulations hardness values, martensite will be formed only up to a certain depth (Figure $\mathbf{3 b}$ and Table 3 ) but not over the whole section of the objects. It is worth noting that differences in the hardness values and hardenabillity obtained in the simulations using Shorin HTC and Narazaki HTC were not detected (Figure $\mathbf{3}$ and Table 3). As it is visible in Figure $\mathbf{3}$ at larger values of HTC (Shorin and Narazaki) the simulation results do not diverge while lower HTC values (Simufact and Hunkel) result in a considerable difference in the predicted hardness and hardenability depth. 


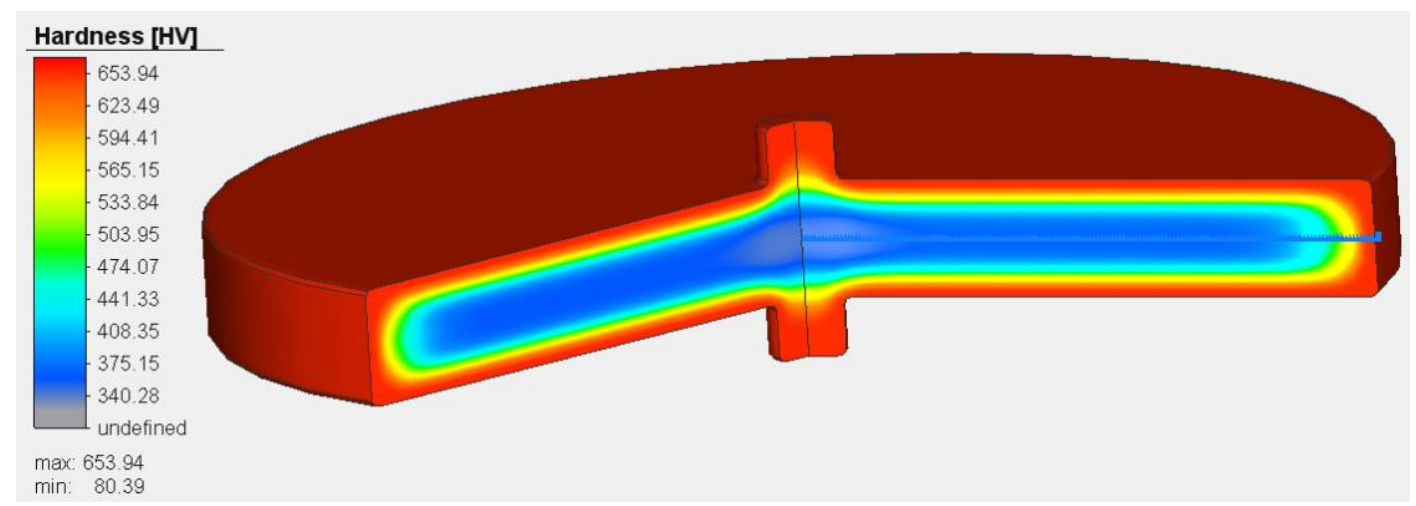

a

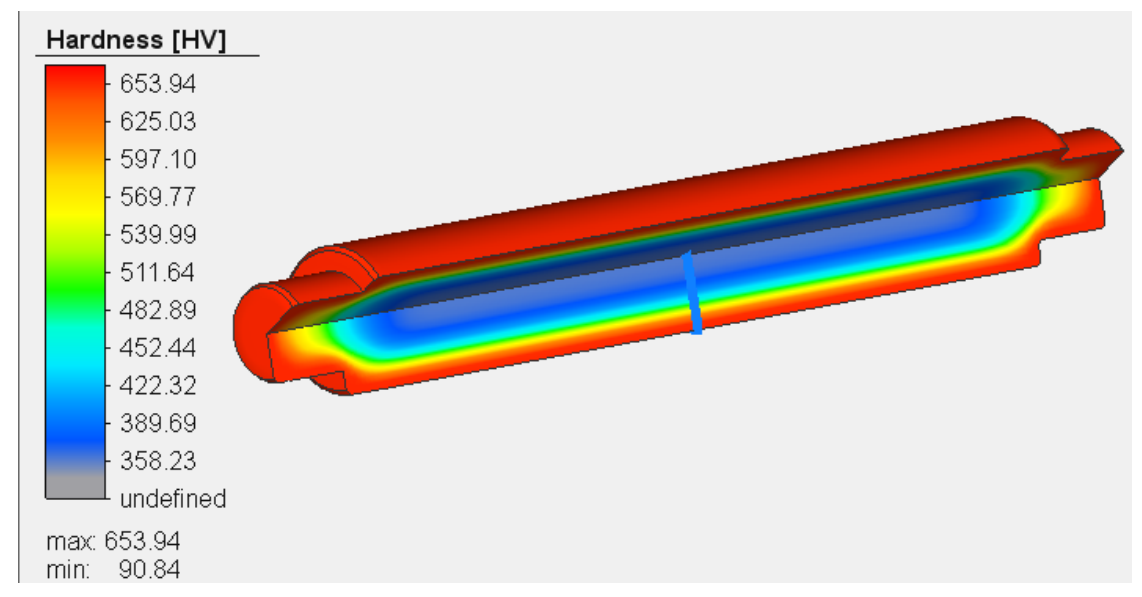

b

Figure 2 Hardness results predicted with Simufact HTC and: a - diameter of $300 \mathrm{~mm}$ and L/D ratio 0.1; $\mathrm{b}$ - diameter of $55 \mathrm{~mm}$ and $\mathrm{L} / \mathrm{D}$ ratio 5

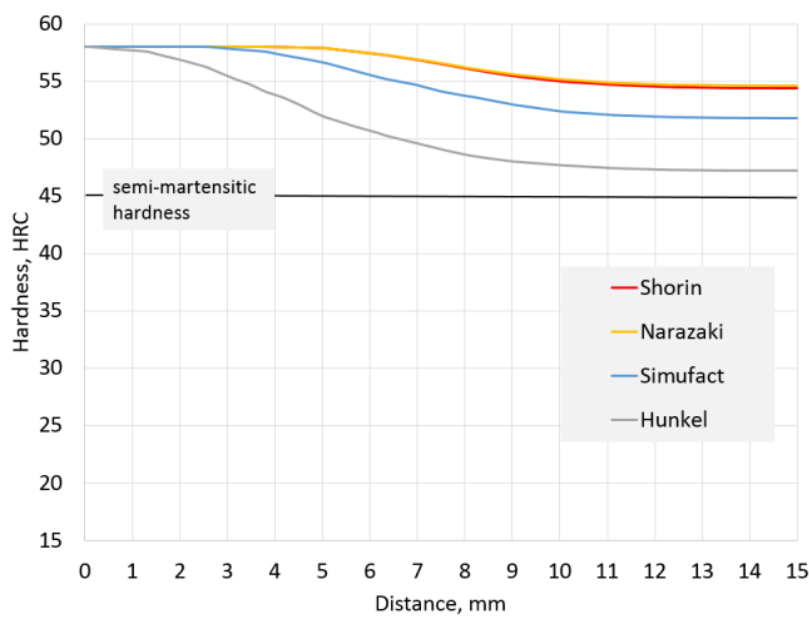

a

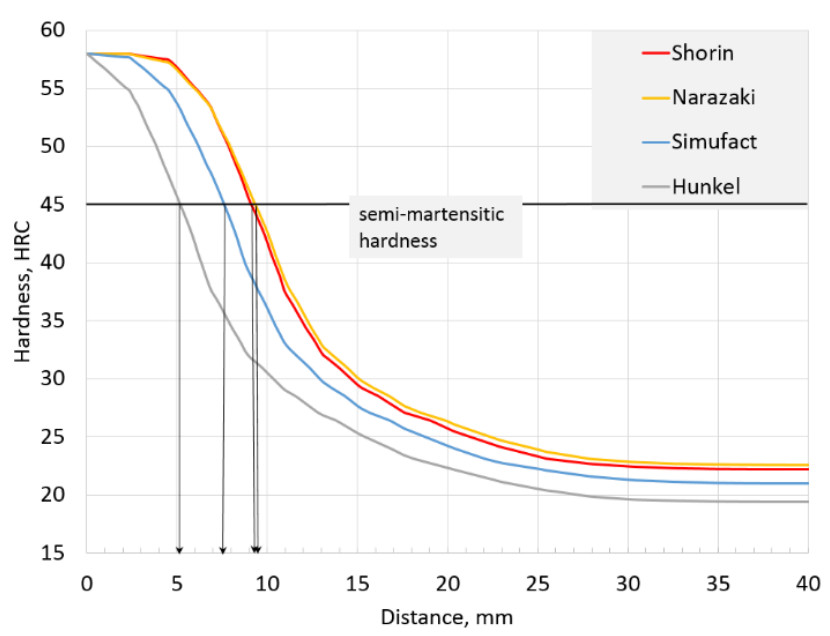

b

Figure 3 Predicted hardness as a function of distance from the surface (hardness profile) in objects with $\mathrm{L} / \mathrm{D}=5$ and: a) $\mathrm{D}=30 \mathrm{~mm}$; b) $\mathrm{D}=80 \mathrm{~mm}$

At $L / D \geq 2$ the maximum difference in depth of hardening is not more than twice, despite the large differences in the input HTC values, and at the larger diameter of $80 \mathrm{~mm}$ it decreases (Table 3). 
Table 3 Influence of HTC and L/D ration on the distance from the surface to semi-martensitic zone (all dimensions are in $\mathrm{mm}$ )

\begin{tabular}{|c|c|c|c|c|c|c|c|c|}
\hline \multirow{3}{*}{$\begin{array}{l}\text { Used HTC values } \\
\text { according to }\end{array}$} & \multicolumn{8}{|c|}{ Distance from the surface to semi-martensitic zone, $\mathrm{mm}$} \\
\hline & \multicolumn{2}{|c|}{$L / D=0.1$} & \multicolumn{3}{|c|}{$L / D=2$} & \multicolumn{3}{|c|}{$L / D=5$} \\
\hline & $D=300$ & $D=400$ & $D=30$ & $D=55$ & $D=80$ & $D=30$ & $D=55$ & $D=80$ \\
\hline Shorin HTC & 19.6 & 10.2 & $-{ }^{*}$ & 12.2 & 9.8 & $-*$ & 12 & 9.5 \\
\hline Narazaki HTC & 20.5 & 10.6 & $-^{*}$ & 11.8 & 9.6 & $-^{*}$ & 11.5 & 9.4 \\
\hline Simufact HTC & 13.7 & 8 & $-^{*}$ & 9.2 & 7.8 & $-^{*}$ & 9.0 & 7.5 \\
\hline Hunkel HTC & 7.3 & 4.9 & $-{ }^{*}$ & 6 & 5.5 & $-*$ & 5 & 5.1 \\
\hline
\end{tabular}

The critical diameters $D_{\text {crit }}$ from simulations with different HTC values was determined considering full hardenability is achieved when the hardness in the centre of the objects is not less than 45 HRC. According to the hardness results obtained from the simulations (not presented here), the quenching simulation using Hunkel HTC gave a critical diameter of $32 \mathrm{~mm}$, the simulation with Simufact HTC - a critical diameter of 36.5 $\mathrm{mm}$, and the simulations with Shorin HTC and Narazaki HTC - a critical diameter of $40 \mathrm{~mm}$.

The analysis of data on the HTC values, available in the the cited here literature, shows that the values of heat transfer coefficient proposed by Hunkel are close to those of high-speed quenching oils. Nevertheless, a large critical diameter of $32 \mathrm{~mm}$ do not correspond to the data form the industrial practice according to which the critical diameter for C45 when mineral oils are used for quenching is of $6 \ldots 12 \mathrm{~mm}$.

\section{CONCLUSION}

The values of heat transfer coefficient given in the specialized literature vary considerably. The difference in the maximum values of the used for the simulations values of HTC is up to 20 times. There is a significant discrepancy between the dependence of the heat transfer coefficient from different sources on the temperature.

The results obtained from simulations with values of HTC from different sources demonstrate a wide divergence in hardenability depth and critical diameters for steel C45. Therefore, the correct choice of the HTC values will have considerable importance for the reliability of the simulations results.

The increase in the HTC values has as a result an increase in the hardenability depth in a nonlinear correlation. The influence of HTC on the hardenability decreases as the values of HTC increase.

\section{ACKNOWLEDGEMENTS}

\section{This research was supported by project 2020 - MTF - 2, funded by the Research Fund of the University of Ruse.}

\section{REFERENCES}

[1] HUNKEL M., LUBBEN, T., HOFFMANN, F., MAYR, P. Using the Jominy End-quench Test for Validation of Thermo-metallurgical Model Parameters. J. Phys. IV France. 2006, vol. 120, pp. 571-579.

[2] HARDIN, R., BECKERMANN, C. Simulation of Heat Treatment Distortion. In 59th SFSA: 93th Technical and Operating Conference. Chicago: IL, 2005.

[3] HASAN, S., PEET, J., JALIL, M. et al. Heat transfer coefficients during quenching of steels. Heat Mass Transfer. 2011, vol. 47, pp. 315-321. 
[4] DEAN, S., MANIRUZZAMAN, M., FONTECCHIO, M., SISSON Jr, R. The Effect of Agitation and Quenchant Temperature on the Heat Transfer Coefficients for 6061 Aluminum Alloy Quenched in Distilled Water. Journal of ASTM International. 2009, vol. 7, no. 1, pp.1-8.

[5] NARAZAKI, M., KOGAWARA, M., SHIRAVORI, A., FUCHIZAWA, S. Accuracy of evaluation methods for heat transfer coefficients in quenching. In: Proc. of 18th Conference ASM International Heat Treating Society. Rosement: ASTM, 1998, pp. 509-517.

[6] SUGIANTO, A., NARAZAKI, M., KOGAWARA, M., SHIRAYORI, A. Validity of Heat Transfer Coefficient based on Cooling Time, Cooling Rate, and Heat Flux on Jominy End Quench Test. In: Materials Science and Technology (MS\&T), STEEL: Recent Developments in Steel Processing. Detroit: MST, 2007, pp. 171-180.

[7] TOTTEN, G., SUN, Y., KOBASKO, N., LIŠČIĆ, B., HAN, S. Advances in Polymer Quenching Technology. In Proceedings of the 1st International Automotive Heat Treating Conference. Puerto Vallarta: Mexico, 1998, p. 3744.

[8] BUCZEK, A., TELEJKO, T. Investigation of heat transfer coefficient during quenching in various cooling agents. International Journal of Heat and Fluid Flow. 2013, vol. 44, pp. 358-364.

[9] YAAKOUBI, M., KCHAOU, M., DAMMAK, F. Simulation of Heat Treatment and Materials With the Use of The Abaqus Software. Metal Science and Heat Treatment. 2013, vol. 55, no. 7 - 8, pp. 386-392.

[10] CHOTĚBORSKÝ, R., LINDA, M. Prediction of Mechanical Properties of Quench Hardening Steel. Scientia Agriculturae Bohemica. 2015, vol. 46, no. 1, pp. 26-32.

[11] KOBASKO, N. Plenary lecture 1: discussion of the problem on designing the global database for different kinds of quenchants. In Proceedings of the 8th international conference on fluid mechanics: 8th WSEAS international conference on Heat and mass transfer (FM'11/HMT'11). Stevens Point: World Scientific and Engineering Academy and Society (WSEAS), 2011, pp.1-11.

[12] LIŠČIĆ, B., SINGER, S. Calculation of the Heat Transfer Coefficient Based on Experiments by the Liscic Probes. Comprehensive Materials Processing. 2014, vol. 12, pp.123-176.

[13] LIŠČIĆ, B., SINGER, S., SMOLJAN, B. Prediction of Quench-Hardness within the Whole Volume of AxiallySymmetric Workpieces of any Shape. Strojniški vestnik - Journal of Mechanical Engineering. 2010, vol.56, no. 2, pp. 104-114

[14] SANCHEZ SARMiENTO, G., GASTON, A., TOTTEN, G. Computational Modelling of Heat Treating Processe by Use of HT-Mode and Abaqus. Latin American Applied Research - an International Journal. 2011, vol. 41, no. 3, pp. 217-224.

[15] PASSARELLA, D., APARICIO, A., VARAS, F., ORTEGA, E. Heat Transfer Coefficient Determination of Quenching Process. Mecánica Computacional. 2014, vol XXXIII, pp. 2009-2021.

[16] SMOLJAN, B., ILJKIĆ, D., POMENIĆ L. Input physical properties in mathematical model of steel quenching. Journal of Achievements in Materials and Manufacturing Engineering. 2013, vol. 58, no. 2, pp.82-86.

[17] SMOLJAN, B., HANZA, S., TOMAŠIĆ, N., ILJKIĆ, D. Computer simulation of microstructure transformation in heat treatment processes. Journal of Achievements in Materials and Manufacturing Engineering. 2007, vol. 24, no. 1, pp.275-282.

[18] SMOLJAN, B., TOMAŠI, N., RUBEŠA, D., HANZA, S. Simulation of hardness distribution in quenched steel specimen. In 13th international scientific conference on Achievements in Materials and Manufacturing Engineering. Gliwice-Wisla: PAN, 2005, pp.597-600.

[19] KUYUCAK, S., NEWCOMBE, P., BRUNO, P., GROZDANICH, R., LOONEY, G. Quench time measurement: as a process control tool, part I. Heat Treating Process. 2005, no. 1-2, pp. 60-63.

[20] KUYUCAK, S., NEWCOMBE, P., BRUNO, P., GROZDANICH, R., LOONEY, G. Quench time measurement: as a process control tool, part II. Heat Treating Process. 2005, no. 3-4, pp. 42-44.

[21] Simufact Forming 15.0, Hexagon.

[22] JMatPro 7.0, Sente Software.

[23] SHORIN, A. Rapport de stage - Centre d'Etude des Structures et des Matériaux Navals (CESMAN), 1997.

[24] ASM International. Handbook Committee, ASM Handbook, Volume 4, Heat Treating. New York: ASM International, 1991. 